\title{
Actividades interdisciplinares de Matemáticas y Música para Educación Infantil
}

\author{
Interdisciplinary activities of mathematics and music education for childhood education
}

\author{
Rocío Chao, $\mathrm{M}^{\mathrm{a}}$ Dorinda Mato, Aurelio Chao, \\ Universidad de A Coruña
}

\begin{abstract}
Resumen
Los beneficios de trabajar la Música y las Matemáticas interdisciplinariamente son innumerables y una enseñanza adecuada puede ayudar a que los estudiantes consigan asociar los conceptos de ambas disciplinas logrando una educación integral y no fragmentada. Con tal motivo, se ha llevado a cabo una experiencia de aula para aprovechar los beneficios de trabajar ambas materias conjuntamente. Los resultados, medidos a través de la observación diaria por parte del profesorado con el que colaboramos, indican que los contenidos correspondientes a un área sirvieron para aprender la otra materia, permitiendo así dar unidad al aprendizaje y mejorar las competencias.
\end{abstract}

Palabras clave: Música, Matemáticas, interdisciplinaridad, actividades.

\begin{abstract}
The benefits of working in an interdisciplinary way Music and Mathematics are endless because and an appropriate education can help students succeed in associating the concepts of both disciplines achieving a comprehensive, unfragmented education. For this reason, we have conducted a classroom experience for the benefits of both subjects worked together. The results, measured by daily observation by teachers with whom we worked, indicate that the contents corresponding to an area served to learn other stuff, thus allowing to drive learning and improving skills.
\end{abstract}

Keywords: Music, Mathematics, interdisciplinary activities.

\section{Introducción}

Frecuentemente se observa en el proceso educativo una desconexión entre las diversas asignaturas; a pesar de que, como indica Canals (2001), no se deben trabajar los contenidos aislados, especialmente en Educación Infantil, si no que conviene que estén relacionados porque, al apoyarse de manera interdisciplinar, en nuestro caso, las Matemáticas y la Música se establecen similitudes con la realidad que se vive, se acerca a la cotidianidad de la vida, se muestra más útil, práctica, dinámica y por encima de todo, se presenta motivadora la enseñanza-aprendizaje (Fernández-Carrión, 2011).

Las investigaciones sobre las matemáticas revelan que se tratan los contenidos marcados por los programas de manera, que parecen frías y cerradas, sin ninguna relación con otras parcelas del conocimiento (Peralta, 1998). Pero, si reflexionamos un poco sobre las actividades que hacemos cada uno desde la hora en que nos levantamos, descubrimos que están más presentes en nuestra vida de lo que nos imaginamos. Cuando miramos el tiempo que falta para la hora de clase, cuando contamos el dinero que necesitamos para subir al autobús, las distancias de casa al trabajo, la cantidad de agua que bebemos, o cuando hacemos cualquier clase de razonamiento estamos utilizando la ciencia matemática. La importancia de esta área es imprescindible, y en todos los niveles educativos, pues contribuyen a desarrollar la comunicación, interpretar el mundo en el que viven y favorecer el desarrollo de conocimientos para poder razonar, aplicar estrategias de análisis y resolver problemas.

Sin embargo, aun reconociendo que el conocimiento matemático ayuda a comprender y manejar la realidad social en la que nos desarrollamos, no gusta a los escolares, las temen y suspenden más que en ninguna otra materia; es más, si pueden las evitan al llegar a cursos superiores (Mato, 2014). La metodología empleada es según Gómez (2012) una causa fundamental en la falta de interés por aprenderla.

En relación con la Música, a nadie le es ajeno el hecho de que forman parte de la vida de los niños aportando innumerables beneficios a su desarrollo cognitivo (Fernández Bravo, 2006). La Educación Musical fomenta el desarrollo de la vida emocional, de las habilidades creativas y expresivas, de la estética y la sensibilidad en general, de la flexibilidad de pensamiento y de la organización temporal. Como indican los estudios más recientes mediante la música nuestro cerebro produce un aprendizaje más acelerado y significativo (Levitin, 2011); estimula el proceso de enseñanza aprendizaje (Chao, Mato y Ferreiro, 2014), y fomenta el desarrollo de la vida emocional, de las habilidades creativas y expresivas, de la estética y la sensibilidad en general, de la flexibilidad de pensamiento y de la organización temporal.

Trabajar interdisciplinarmente nos motivó a realizar una investigación para analizar ambas disciplinas en los alumnos de 0 a 6 años durante el curso 2013-2014. Los resultados del análisis demostraron, entre otras cuestiones, que el trabajo interdisciplinar no se lleva a cabo en los colegios de la ciudad. Sin embargo, los maestros reclamaron estrategias para implantar tal metodología en sus centros pues reconocían las ventajas que se aportarían mutuamente ambas materias. Una de las razones que esgrimían para no hacerlo es la escasa formación del profesorado, principalmente en educación musical; lo que según Pascual Mejía (2006) menoscaba el papel que juega en la formación integral del alumno.

Estos resultados nos impulsaron a diseñar en el curso 2013-2014 una propuesta didáctica asentada en actividades realizadas en base al tratamiento de la música y las matemáticas de manera conjunta. 


\section{¿Qué relación existe entre la Música y la Matemática?}

Desde luego, las matemáticas están en la propia esencia de este arte; no en vano, la manera de elegir las notas musicales, su disposición, las tonalidades, los tiempos e incluso gran parte de los métodos de composición son pura matemática (Moreno, 2008). Además, la enseñanza musical en edades tempranas ayuda al niño a conseguir de forma más completa y lúdica una serie de funciones sensomotrices y perceptivas (Fernández-Carrión, 2011).

Por otra parte, el currículum de Educación Infantil hace explícito que, a pesar de que el contenido del mismo está organizado en tres áreas de conocimiento, el trabajo con los alumnos no se tiene que presentar de manera parcelada. Lo que propone la ley es crear espacios de aprendizaje que relacionen los contenidos de las diferentes áreas, a fin de que se contribuya al desarrollo de los niños, acercándolos a la interpretación del mundo, dando significado y facilitando su participación activa (Edo, 2012).

\section{Objetivos}

El objetivo que nos planteamos con esta investigación es analizar si en las aulas de Educación Infantil mejora el rendimiento de los alumnos trabajando interdisciplinariamente Matemáticas y Música.

\section{Muestra}

La muestra está formada por 119 estudiantes de 5 años repartidos en 6 aulas de Educación Infantil de sendos centros públicos de la provincia de A Coruña.

\section{Procedimiento}

Se contacta con doce centros para llevar a cabo el estudio, consistente en un plan de actividades en las que los alumnos trabajaran contenidos de las dos áreas al mismo tiempo. Buscábamos una situación amplia que ofreciese interés y significado para los niños y en la que el maestro fuese capaz de analizar, reconocer y potenciar la relación y los beneficios que la conjunción matemáticas-música supone.

Solo 6 maestros respondieron a nuestra solicitud en el plazo marcado, colaborando con mucho interés con nosotros. Nos reunimos en tres ocasiones los maestros y los investigadores; dos, en el mes de enero, antes de la puesta en marcha de la investigación para llegar a acuerdos y diseñar las actividades y una posterior al estudio en el mes de marzo. Nosotros elaboramos la propuesta y les pedimos la opinión a los maestros. Se aplicó en el mismo espacio de tiempo y cada profesor en su correspondiente centro. En la tercera reunión se analizó con detalle todo lo ocurrido en cuanto a resultados de aprendizaje, motivación de los niños, actividades, ventajas y desventajas halladas.

Los resultados, medidos a través de la observación diaria por parte del profesorado colaborador, indican que los contenidos correspondientes a un área sirvieron para aprender la otra materia, permitiendo así dar unidad al aprendizaje y mejorar las competencias.

\section{Propuesta Didáctica}

La propuesta se ha planificado para el segundo trimestre porque los niños ya conocen la dinámica de la escuela y las diferentes formas de trabajo del aula. Durante cuatro semanas se desarrollaron las sesiones, procurando mantener el mismo día y momento de la semana para distorsionar lo mínimo las rutinas del aula.

Para ello realizamos diferentes actividades con los instrumentos musicales, las notas, canciones, intensidad, timbre, etc. relacionados con los conceptos matemáticos de forma, tamaño y números,...

Las actividades son abiertas puesto que se aprovechó cualquier situación de aprendizaje en la interacción con los niños para dar respuesta a sus preguntas.

Aunque las actividades están directamente relacionadas con la música y las matemáticas, trabajamos contenidos variados pertenecientes a diferentes áreas. Así, tratamos aspectos de psicomotricidad (ej. realizamos actividades de relajación), de lenguaje (ej. expresamos verbalmente nuestras ideas, sentimientos y opiniones durante la asamblea) y socio afectivos (compaginamos el trabajo en gran grupo, en pequeño grupo $\mathrm{o}$ en parejas, estrechando lazos afectivos $\mathrm{y}$ disfrutando de la actividad).

En este sentido, debemos hacer hincapié en la importancia de cuidar la progresión de los contenidos. Nuestra unidad didáctica formula una secuencia lógica de actividades, estructurada en sesiones. Cada una de las sesiones consta de tres fases: en la asamblea general realizamos una actividad introductoria en la que presentamos contenidos. Posteriormente, tiene lugar la actividad de desarrollo en la que los niños y niñas deben demostrar lo que han aprendido en la fase anterior. Dicha fase posee un mayor grado de dificultad donde la expresión corporal adquiere protagonismo. Por último, destacamos la fase de relajación en la que se llevan a cabo actividades de distensión, pero sin perder la conexión con la temática central del programa.

Debemos destacar que todas las actividades planteadas tienen un carácter lúdico. Es ideal en estas edades basar el aprendizaje a través del juego, ya que es el motor del desarrollo emocional, intelectual y social, e influye en las estructuras de conocimiento y en las relaciones con el entorno.

El docente debe favorecer un clima de seguridad y confianza. El maestro cuando los niños y niñas realizan las actividades programadas, debe estar en todo momento a disposición de los alumnos ayudándolos a desarrollar su actividad, recordando las reglas colectivas y orientado a aquellos que están bloqueados proporcionándoles nuevas pautas de actuación.

\section{Plan de actividades}

\section{Sesión 1: La luna.}

Objetivos:

Realizar sencillos patrones rítmicos con el cuerpo o instrumentos. Adecuar su propio cuerpo a los cambios entre rápido y lento y todos sus grados intermedios. Comprender y dramatizar magnitudes de cerca/lejos.

\section{Contenidos:}

El tiempo: Rápido-lento, orientación espacial, tamaño, atención.

Materiales: Cuentos "Papá, por favor, achégame a lúa" y "Lúa”, canción BSO "2001. Odisea en el espacio", 
instrumentos de percusión (sonajas, panderos, panderetas, triángulos, cajas chinas, etc).

\section{Desarrollo:}

- Actividad de introducción.

Se realizará durante una asamblea general. Como cada día, el alumnado se dispondrá sentado en el suelo formando un círculo de manera que todos se vean entre sí y puedan atender a las explicaciones.

En este momento se contará el cuento "Papá, por favor, achégame a lúa” y se comentará grupalmente.

- Actividad de desarrollo.

A partir del cuento leído se contará con ayuda de los niños introduciendo un patrón rítmico y una melodía sencilla. Se repartirán instrumentos de percusión a las niñas y niños e intentarán seguir el ritmo con ellos. Utilizando el mismo cuento, se dejarán a un lado los instrumentos y se trabajará la lateralidad realizando el patrón rítmico con la derecha cuando el elemento sea "luna" y con la izquierda cuando sea diferente (sol, caracol, girasol, etc.)

Seguidamente, se pondrá la BSO de "2001. Odisea en el espacio", Así habló Zaratustrade R. Strauss, y se animará a niñas y niños a que caminen por el espacio al ritmo de la música simulando que están en la luna, después se les entregarán sonajas para que las hagan sonar a la vez que caminan.

- Actividad de relajación.

Los niños y niñas se disponen tumbados por todo el aula, una vez estén relajados comenzarán a recordar partes de la sesión y posteriormente, con los ojos cerrados, se instará al alumnado a que haga estiramientos con brazos y piernas como intentando llegar a la luna, igual que en el primer cuento.

\section{Evaluación:}

Intenta seguir el ritmo con su cuerpo o con los instrumentos. Escucha atentamente los cuentos o explicaciones del maestro o maestra. Interpreta con su cuerpo los cambios de velocidad que experimenta la música. Comprende la diferencia entre términos opuestos como rápido/lento o cerca/lejos.

\section{Sesión 2: BoomWhackers.}

\section{Objetivos:}

Aprender a improvisar con recursos instrumentales, espaciales y corporales. Diferenciar y reconocer los conceptos: rápido-lento. Clasificar objetos por semejanzas en función de color y tamaño.

\section{Contenidos:}

-Ritmo, clasificación, memoria, comparación: más grande-más pequeño, escala musical, altura, armónicos y acordes, acordes.

Materiales: Dispondremos de varios grupos de BoomWhackers, un tubo sonoro de armónicos y un ordenador.

\section{Desarrollo:}

- Actividad de introducción.

Después de realizar las rutinas diarias les pondremos un vídeo del grupo Mayú-maná. Tras el visionado intentaremos fomentar la participación del alumnado a través de un diálogo con preguntas del tipo: ¿Qué os ha parecido el vídeo? ¿Os ha gustado la música? ¿Utilizan instrumentos? ¿Creéis que podemos hacer música nosotros también? ¿Con qué objetos?

- Actividad de desarrollo.

Después del debate mostraremos unos tubos sonoros denominados BoomWhackers. Dispondremos de varios grupos de tubos de forma que haya uno para cada niño o niña. Será preciso disponer de gran espacio en el aula para que los discentes puedan experimentar con libertad, puedan estar lo suficientemente alejados para discriminar los distintos sonidos que producen los tubos.

Más tarde explicaremos en qué consisten y cómo suenan estos tubos sonoros. Después, entregaremos un tubo a cada niño y niña, de forma que habrá varios tubos de cada nota. Los niños se agruparán entonces por colores, de forma que cada grupo de niños y niñas corresponderá a una nota musical determinada. Posteriormente, estableceremos un patrón rítmico para cada nota o grupo. De esta manera, el alumnado podrá crear una melodía simple conocida por ellos mismos y reconocer que están creando música igual que en el vídeo visionado en el aula. Introduciremos la exploración de los armónicos. Para ello, los niños y niñas tocarán sonidos diferentes simultáneamente.

Actividad de relajación.

Para finalizar la sesión se realizará una actividad de relajación relacionada con el ritmo. Los alumnos y alumnas se sentarán en círculo en el suelo del aula y se colocarán por parejas. Un componente de la pareja se sentará en el suelo con las piernas cruzadas y el otro componente se colocará detrás de él, de rodillas.

Posteriormente, explicaremos que pondremos música con diferentes ritmos: rápido y lento. Ellos deberán realizar un masaje a su compañero o compañera que está sentado en el suelo siguiendo los diferentes ritmos de esa música. Todos los niños y niñas deberán estar en silencio para poder escuchar la música, que estará en un volumen bajo, y contribuir a la relajación de todo el alumnado. Cuando termine la melodía, se hará un intercambio de roles.

\section{Evaluación:}

Discrimina diferentes ritmos. Es capaz de expresarse a través del ritmo. Relaciona el ritmo a la práctica de su movimiento corporal. Improvisa con diferentes instrumentos musicales, recursos espaciales y corporales. Agrupa objetos en función de su color y tamaño. Conoce la diferencia entre los conceptos: rápido/lento.

\section{Sesión 3: ¡Creamos melodías!}

\section{Objetivos:}

Conocer y usar códigos gestuales a partir de sonidos. Aprender a establecer un orden a través de la secuencia. Desarrollar los procesos básicos de atención, observación y memoria. Conocer la utilización del monograma.

\section{Contenidos:}

- Secuencia, atención, memoria, observación, ritmo, tempo, sonido/silencio, monograma.

Materiales: Cartulinas de diferentes colores y tamaños; folios; imágenes con varios dibujos; rotuladores; forro transparente para plastificar; pegamento; tijeras y velcro; y pelotas de espuma de tamaño mediano. 


\section{Desarrollo:}

- Actividad de introducción.

En el momento de asamblea llevaremos a cabo una actividad relacionada con un juego de manos popular, que combina la acción de mover las manos al compás de una canción.

- Actividad de desarrollo.

"Creamos melodías" es un juego musical que debe desarrollarse utilizando por un lado un dado que tiene en cada cara una imagen, a saber: una palmada, un puño cerrado, dos dedos, una chica con el dedo en los labios simulando pedir silencio y una bombilla; y por otro lado tiene una cartulina grande en la que están dispuestos tres sobres que contienen tarjetas de colores con las mismas imágenes que se han mencionado anteriormente, además en la parte inferior hay un monograma de velcro para que los niños y niñas posteriormente coloquen las tarjetas formando una secuencia. El juego comenzará dividiendo la clase en grupos de cinco niños y niñas. En el primer grupo cada pequeño y pequeña tirará el dado, dependiendo de la imagen que salga deberá coger la tarjeta correspondiente y pegarla en el monograma.

Todas las imágenes representan una acción: o Una palmada: darán palmadas simulando aplausos. o Puño cerrado: percutirán la mesa con el puño cerrado. o Dos dedos: percutir con 2 dedos la palma de la mano.

o Una chica con el dedo en los labios simulando pedir silencio: harán el mismo gesto sin decir nada.

o Una bombilla: inventarán un sonido.

o Cuando la secuencia del monograma se complete todos los grupos representarán esas acciones. A continuación, se repetirá el mismo proceso con el segundo grupo y así hasta completar todos los grupos que se hayan formado.

- Actividad de relajación.

Para cerrar esta sesión haremos una actividad de relajación en el espacio destinado a las asambleas, utilizaremos una música suave y formaremos parejas.

Un niño o niña se tumbará boca abajo y su pareja rodará lentamente la pelota de espuma por su espalda y por las piernas para tener la sensación de que está recibiendo un masaje. Al finalizar intercambiarán los papeles de forma que todos reciban su masaje.

\section{Evaluación:}

Respeta el turno de espera. Identifica la imagen y sabe aplicar la acción correspondiente. Controla la intensidad de los movimientos que tenga que llevar a cabo. Sigue el orden de las secuencias. Es capaz de memorizar las diferentes imágenes.

\section{Sesión 4: Carrera de caballos.}

\section{Objetivos:}

Conocer la noción temporal trabajando conceptos como rápido-lento. Interpretar la forma de desplazamiento de diferentes animales a través de secuencias de movimientos y ritmos. Sentir el movimiento y el ritmo como recursos para la expresión y la comunicación.

\section{Contenidos:}

- Atención, memoria, orden, tempo, compás, pulso.

Materiales: Utilizaremos un ordenador y una silla para cada alumno y alumna.

\section{Desarrollo:}

- Actividad de introducción.

En asamblea enseñamos una serie de diapositivas en las que aparecerán animales acuáticos y terrestres como: delfín, tortuga, leopardo, caballo, águila, pulpo, caracol... A partir de ellas iremos analizando diferentes aspectos de estos animales. Prestaremos especial atención a la forma y a la velocidad con la que se desplazan.

Tomaremos como ejemplo el caballo para explicar los indicadores de tiempo rápido, tranquilo y lento. Sentados sobre la alfombra y con las piernas cruzadas imitaremos la forma de caminar de este animal. Haremos chocar las manos con la parte superior de las piernas. Explicaremos al alumnado que los caballos tienen tres modos de desplazamiento e imitaremos cada uno. Al "paso" los niños y niñas realizarán golpes de forma lenta. Se trata de un caminar a cuatro tiempos, por lo que el caballo realiza cuatro golpes igualmente espaciados. En el "trote" el alumnado saltará a dos tiempos realizando golpes algo más rápidos pero de forma tranquila. Por último, con el "galope" la velocidad de los golpes será muy rápida, intentando andar a tres tiempos.

- Actividad de desarrollo.

Nos sentamos todos en sillas haciendo un círculo para llevar a cabo la actividad. Se trata de simular una carrera de caballos. La maestra será la encargada de dirigirla convirtiéndose en comentarista deportiva. A su vez, cada niño y niña simulará ser un jinete y contará con su propio caballo (la silla).

El comentarista, utilizando la voz y la mímica, describirá una serie de situaciones que irán aconteciendo a lo largo de la carrera. Los alumnos y alumnas tendrán que imitar los diferentes gestos siguiendo el ritmo que marque la profesora.

A continuación exponemos las diferentes acciones que los pequeños y pequeñas deberán emular:

Posición de salida. Permanecemos encerrados en el cajón, sentados en la silla y con las manos delante, simulando que las puertas están cerradas.

o Trotamos. Hacemos chocar las manos con la parte superior de las piernas. Teniendo en cuenta la forma que tiene el caballo de caminar los pequeños jinetes utilizarán diferentes velocidades (rápido, tranquilo, lento). Las explicaciones dadas durante la actividad introductoria cobrarán importancia. Cada vez que el comentarista enuncie "al paso", "al trote" o "al galope" el alumnado tendrá que poner en práctica lo aprendido anteriormente. o Saludamos a alguien que nos encontramos por el camino. Descansamos un instante para levantar la mano y hacer el gesto correspondiente al saludo.

o Saludamos a un chico o chica guapo. Repetimos el gesto anterior, pero guiñamos un ojo.

o Pisamos un charco de agua. Simulamos el sonido dando palmadas.

o Pasamos por debajo de un túnel. Nos agachamos, pero seguimos trotando golpeando el pecho.

o Trotamos encima del caballo. Nos subimos a la silla y golpeamos las piernas. La velocidad dependerá de las indicaciones del comentarista.

o Cambiamos de caballo. Abandonamos nuestra silla ocupando la del compañero o compañera de al lado. 
o Sprint final. Una mano sigue golpeando la pierna y la otra la utilizamos como sistema de frenada dando pequeños cachetes en el culo.

o Foto finish. La carrera termina cuando el comentarista grita esta frase. Los niños y niñas deberán adquirir una pose para la foto y quedarse quietos.

- Actividad de relajación.

Dado el carácter dinámico de la actividad "Carrera de caballos" proponemos al alumnado que se relaje. Nos tumbaremos en el suelo, cerraremos los ojos e intentaremos dejar la mente en blanco. De fondo sonará la canción "Arrival of thebirds \& Transformation", de The Cinematic Orchestra. Permaneceremos en esta posición unos dos minutos y medio. Coincidiendo con la segunda parte de la canción ("Transformation") el docente pedirá al alumnado que se levante despacio e imiten la forma de desplazamiento de algún animal visto durante la asamblea inicial. Caminarán por el aula lenta y tranquilamente siguiendo el compás de la música.

\section{Evaluación:}

Es capaz de memorizar los diferentes gestos. Distingue los tempos musicales rápido-tranquilo-lento. Interpreta movimientos generados al ritmo de la música u otros sonidos. Expresa emociones a través de movimientos corporales.

\section{Resultados}

La valoración de los avances y logros de los niños fue espectacular en todos los casos. Se llevó a cabo un seguimiento continuo, por parte de los docentes, a través de la observación.

Los aprendizajes adquiridos y el ritmo y las características de la evolución de cada discente demostró las ventajas de diseñar conjuntamente las actividades, ya que alcanzaron los objetivos propuestos el $100 \%$ de los niños. Tenemos que destacar que se respetó el ritmo de cada uno, así como si nivel de conocimientos iniciales y las características individuales.

Los aprendizajes de cada materia fueron superados en cuanto a contenidos específicos y en relación a las diferentes capacidades específicas de cada una.

La evaluación las actividades realizadas, la metodología a lo largo de cada unidad, la propia práctica docente, motivación de todos el alumnado subraya el éxito de la propuesta.

Por último, cabe destacar que el profesorado participante valoró muy positivamente esta experiencia, manifestando su deseo de tener nuevas propuestas, debido tanto a los resultados obtenidos, como al entusiasmo con el que ha trabajo su alumnado.

\section{Conclusiones}

A tenor de los resultados, son muchos los beneficios que suponen trabajar la música y las matemáticas de una manera conjunta. Este modo de tratar ambas materias hace que el alumnado llegue a comprender más profundamente los diversos conceptos de las mismas, teniendo la capacidad de relacionarlos, desarrollando así una visión interdisciplinar, visión con la que se debería enfocar la metodología de la educación en esta etapa educativa. Asimismo, se potencia el desarrollo integral del alumnado, ya que la música no sólo ayuda a la comprensión de conceptos matemáticos, sino que favorece el progreso en todos los ámbitos educativos.

Este ha sido sólo un ejemplo de las posibilidades que tiene la conjunción de estas dos materias, las actividades y experiencias que podrían salir del binomio música y matemáticas son infinitas. Todo depende de la creatividad de profesores y alumnos y de la capacidad de adaptarse a los recursos que su entorno les proporciona.

\section{Referencias}

Canals I Tolosa, M. A. (2001). Vivir las matemáticas. Barcelona: Octaedro - Rosa Sensat.

Chao, R.; Mato, M. D.; Ferreiro, F. J. (2014). Music therapy in adolescent disruptive behavior. Procedia. Social and Behavioral Sciences,132, 608-614.

Edo, M. (2012). Situaciones interdisciplinarias para el desarrollo del pensamiento matemático en Educación Infantil en la formación de maestros. En $M$. Marín-Rodríguez; N. Climent-Rodríguez (eds.), Investigación en Educación Matemática. Comunicaciones de los grupos de investigación. $X V$ Simposio de la SEIEM (pp. 427-453). Ciudad Real: SEIEM.

Fernández Bravo, J. A. (2006). Didáctica de la Matemática en Educación Infantil. Madrid: Grupo Mayéutica.

Fernández-Carrión, M. (2011). Música y matemáticas: conexiones curriculares para un mayor éxito educativo disponible el 24/07/2013 en: http://recursostic.educacion.es/artes/

Gómez, P. (2012). Matemáticas y música en niños pequeños. RSME (Real Sociedad Matemática Española). Universidad Politécnica de Madrid.

Levitin, D. (2011). Tu cerebro y la música. Barcelona: RBA.

Mato, M. D. (2014). La afectividad hacia las Matemáticas. Editorial Netbiblo. Charlston, S.C.

Moreno, A., (2008). Importancia de la Educación Musical en infantil. Innovación y experiencias Educativas. Granada, ISSN 1988-6047.

Pascual Mejía, P. (2006). Didáctica de la Música en educación infantil. Madrid: Pearson Pentice Hall.

Peralta, J. (1998). Las matemáticas en el arte, la música y la literatura. Tendencias pedagógicas especial $\mathrm{n}^{\circ} 2$. Departamento de Didáctica y Teoría de la Educación de la Universidad Autónoma de Madrid. 